\title{
Torn between responsibility and loyalty: how the veterinarian profession designs antibiotic resistance policies that shake its foundations
}

\author{
Muriel Surdez $^{1} \cdot$ Lorène Piquerez $^{1}$ (D) Alexandre Hobeika ${ }^{2}$
}

Received: 3 May 2019 / Accepted: 13 September 2020 / Published online: 3 November 2020

(C) The Author(s) 2020

\begin{abstract}
Antimicrobial resistance (AMR) policies, which aim to redefine how antibiotics are used, reshape the veterinary profession's relationships in at least two ways. The policies can give state veterinarians greater power over practising veterinarians and thus change the relationship between the profession and the government supposed to regulate it. The policies also call for coordination with other relevant professionals, mainly in the areas of human medicine and food safety, which can limit the veterinary profession's autonomous decision-making. Based on a survey of veterinarians working at different levels of the administration and their non-veterinary colleagues in Switzerland, it is shown that AMR policies, by strengthening the administration's planning and supervisory functions, do contribute to increased state control of the veterinary profession. However, this shift is limited because implementing the policies requires negotiating with representatives of the profession.
\end{abstract}

Keywords Veterinary profession - Antimicrobial resistance $\cdot$ AMR $\cdot$ Veterinary public health $\cdot$ Public policy $\cdot$ Professional regulation

Lorène Piquerez

lorene.piquerez@unifr.ch

Muriel Surdez

muriel.surdez@unifr.ch

Alexandre Hobeika

alexandre.hobeika@gmail.com

1 Département des sciences sociales, Université de Fribourg (Suisse), Bâtiment PR21 - Bureau G304, Fribourg, Switzerland

2 CIRAD, Montpellier, France 


\section{Introduction}

In the past 15 years or so, antibiotic resistance has become the public problem that epitomises the 'One Health' approach promoted by international organisations (World Health Organization (WHO) 2014, 2015; World Organization for Animal Health (OIE) 2016; European Commission 2017). This approach, which aims to closely link human, animal, plant and environmental health policies (Hinchliffe 2015), is presented as a new and necessary way of addressing the complex and interlinked challenges of health policies in all their dimensions (Woods et al. 2017). It also aims to help break down the barriers between specialisms and between administrations (Chien 2013) that are seen as a cause of dysfunctions and health crises. In the field of antimicrobial resistance (AMR) policies, developing a 'strategy' that encompasses antibiotic use in human and veterinary medicine is considered a crucial step by administrations and professionals in charge of developing 'action plans' and, at the international level, to be a prerequisite for the success of AMR policies. The main argument is that efforts must focus on both human and animal health, since resistant bacteria cross the species barrier, and antibiotics, sometimes of the same class, are used for both.

Public policies that address the problem of antibiotic resistance therefore have the potential to substantially affect the dynamics of the veterinary profession, even if they do not 'regulate' it in the narrow sense of the term (Bonnaud and Fortané 2018, Hobson-West and Timmons 2016). Indeed, they concern the prescription of antibiotics (Fortané 2016; Jensen et al. 2018), which is an integral part both of the practice of urban and rural veterinarians and of their professional autonomy-although, as these public policies focus on rural veterinarians specialising in livestock, this article will concentrate on the latter. It should be added that veterinarians working within administrations are key to developing and implementing action plans against antimicrobial resistance, as has been the case with Switzerland's 'Strategy on Antibiotic Resistance' (see Box 1). This article examines these state veterinarians' characteristics and position statements in order to provide a sociological analysis of the trajectories of public policies against AMR and of the instruments used. ${ }^{1}$ More specifically, we aim to show how these state veterinarians interact with professional veterinary organisations and practising veterinarians. Rather than assume that the veterinary profession is a homogeneous one, this approach focuses on different segments of the veterinary profession in order to sketch out how One Health AMR policies have contributed to breaking down boundaries and transforming this professional group and its regulation.

\footnotetext{
${ }^{1}$ Work that develops this type of analysis to shed light on contemporary veterinary public health policies remains scarce (Alam 2007; Grant and Greaves, 2009; Ollivier 2013 on the European veterinary administration).
} 
The Swiss strategy to combat antibiotic resistance, known by the acronym StAR, was approved by the Swiss Federal Council in 2015 (FOPH 2015; FOPH and FSVO, 2015), after being formulated rather late compared to other countries. It involves four federal administrative offices in coordination (see below). Based on the One Health approach, it includes eight fields of activity:

- 'monitoring' of the progression of resistance in both human and veterinary medicine;

- 'prevention', which limits infections pre-emptively, notably through vaccines;

- 'appropriate use' of antibiotics in accordance with guidelines for their prescription;

- 'the fight against resistance' proper to minimise the spread of resistant germs;

- 'research and development", with the aim of filling existing gaps and generating new research, in particular around new antibiotics or the transmission mechanisms of resistance;

- 'professional and interdisciplinary cooperation" to successfully combat problems;

- 'information and education" to raise awareness among professionals and the general public;

- 'implementation of the general conditions' for maintaining the efficacy of antibiotics.

In 2018, a first review showed that the efforts undertaken have contributed to reduced antibiotic use in both human and animal medicine. ${ }^{2}$

Box 1 An example of a national plan: the StAR

Beyond these declarations of intent (Box 1), this article examines how relationships between different types of actors result in some of these fields of activity being prioritised over others as implementation of the StAR progresses. It focuses on veterinarians within the state administration in their pivotal role between the profession and the state in developing and implementing public action in veterinary medicine. In sociology of professions terms, these veterinarians working for the authorities can be described as 'professional bureaucrats', i.e. members of a profession (recognisable by their prestige, their certifications, their capacity for self-regulation) who have the particularity of practising within bureaucratic organisations. Like other professionals of this type (doctors, teachers, lawyers), veterinary bureaucrats face dilemmas in their daily work due to conflicts between their roles as members of the veterinary profession and of the state administration-Noordegraaf (2007 and 2013) has described them as 'hybrid professionals'; another term is 'public veterinarians'. Public veterinarians can exercise state power over practising veterinarians by acting as advisors and experts in standard setting (legislative and project design, planning activities) or by performing frontline tasks (administrative enforcement tasks, inspections of veterinary practices, farms or slaughterhouses). In operating more or less autonomously within the profession as well as within the state administration, this group blurs the boundary between the two. This makes it possible to study the articulation between state regulation and professional regulation, two modes of regulation that the sociology of professions ${ }^{3}$ and public policy analysis have long considered distinct if not antagonistic (but see Demazière 2018; Bezes et al. 2011).

\footnotetext{
${ }^{2}$ Between 2009 and 2017, there was a 50.7\% drop in antibiotic sales, particularly in the veterinary field, with a further drop of $1.3 \%$ in $201 \mathrm{FSVO} 2018$ ).

${ }^{3}$ However, neo-Weberians have shown that self-regulation of prestigious professions is carried out through legal mechanisms endorsed by the authorities (Demazière 2018).
} 
The management of antibiotic resistance and antibiotic use is transforming the veterinary profession. How do the various segments and specialisations within the profession cope with their acknowledged core ability to prescribe medicinal products being called into question (Abbott 1988; for human medicine, see Freidson 2001)? Are state veterinarians in a position to impose a 'state vision' on the proper use of antibiotics on their private practice colleagues, in particular rural ones who specialise in livestock and on whom antibiotic resistance policies primarily focus? ${ }^{4}$ Do they approach other groups of 'professional bureaucrats' while developing policies? Or do they resist change because they share the concerns of their veterinary peers?

To answer these questions, this article focuses on veterinary bureaucrats and their relationships with other government professionals who deal with animal health or food products of animal origin. We draw on a survey of reforms in food safety inspection. ${ }^{5}$ In this context, we met twenty-six public veterinarians working either in the national administration in Bern or in one of four cantonal administrations. Hierarchically, they are heads of departments, heads of units or laboratories or employees; we interviewed some retired public veterinarians due to their long career. We also interviewed nine chemical engineers, six food engineers, seven chemical laboratory technicians and six other specialists (doctors, biologists, lawyers working in the same administrative units). The interviewees' socio-professional characteristics and careers were analysed using the SPSS programme. ${ }^{6}$ A textual analysis of the interview transcripts was carried out using Atlas.ti software. We also refer to the administrative documents (reports, action plans, brochures) produced by these professionals. Although we did not interview practising veterinarians in this initial project, we supplemented our data with an analysis of the reports of the Swiss Veterinary Society (SVS) and additional interviews with professionals more directly involved in the implementation of StAR - three veterinarians who are members of the SVS, three agricultural engineers and a federal veterinarian in charge of the database on veterinary medicinal products.

After presenting how the veterinary profession is organised in Switzerland, including in the administration, we show that this professional group did not initiate the management of antibiotic resistance, but at first simply reacted to the regulation of veterinary medicinal products that preceded the StAR (Part 1). In a second step, as part of the development of AMR policy, veterinarians at the top echelons of central government were given responsibility for unavoidable reforms. Despite calls for increased collaboration with actors in human medicine and throughout the food chain, veterinary bureaucrats retained control over the implementation of measures relating to veterinary medicine (Part 2), which resulted in other professional bureaucrats leaving the animal side of the problem entirely to the veterinary profession. Moreover, public veterinarians have found it difficult to put into practice their greater control over the sale and use of antibiotics, due to a lack of bureaucratic resources and

\footnotetext{
${ }^{4}$ The main reasons that antibiotic resistance policies focus on livestock veterinarians are, firstly, that the problem of antibiotic resistance is primarily framed as a problem of the quantity of antibiotics prescribed and, secondly, that veterinary public health policies more broadly generally concern livestock. Small pets are considered to belong to the private sphere, where regulatory intervention by the state is more difficult to justify.

5 'Cooperation and concurrence between professional bureaucrats. The case of food safety reforms in Switzerland', project financed by the Swiss National Science Foundation (No 10001A_159308, 2015-2017).

${ }^{6}$ SPSS (Statistical Package for Social Sciences) is a statistical analysis and forecasting software specifically designed for the social sciences that allows descriptive statistics of social trajectories to be produced.
} 
Table 1 Distribution of veterinary bureaucrats by institution

\begin{tabular}{lll}
\hline Territorial level & Position & Approximate number \\
\hline Cantonal & Heads of department, chief assistants & 40 \\
Cantonal & Employees & 80 \\
Federal (FSVO) & Heads of units/sections + employees & 20 \\
Both & Retired & 30 \\
& Total: & 170 \\
\hline
\end{tabular}

to their membership of the veterinary profession. As a result, the more closely antibiotics are controlled by public policy, the more state veterinarians negotiate with representatives of practising veterinarians (Part 3). We will conclude that the empowerment and legitimisation of the bureaucratic segment of the profession are far from linear processes.

\section{Morphology of the veterinary profession}

In Switzerland, the federal government (national level) is organised into seven major 'ministries', called Federal Departments. Within the Federal Department of Home Affairs, veterinarians work in the Federal Food Safety and Veterinary Office (FSVO) and the Federal Office of Public Health (FOPH). This is a relatively recent reorganisation. Until 2015, the Federal Veterinary Office was part of the Federal Department of Economic Affairs, at the same hierarchical level as the Federal Office for Agriculture (FOAG). A liaison structure between the offices, the Federal Food Chain Unit, based at the FSVO, was created in 2007 following the mad cow crisis.

Separating veterinary affairs from agriculture, as has been done elsewhere in Europe (Alam 2009; Janning 2008), does not lead to an increase in the number of posts for veterinary bureaucrats at the federal level (Table 1). Indeed, many public veterinary tasks fall within the remit and budgets of the cantons. In total, there are approximately 20 active federal veterinarians and about 120 cantonal veterinarians, distributed as follows:

In other countries, public veterinarians may be managed by generalist civil servants who impose their own health or management standards (Alam 2007, for France and Great Britain). In Switzerland, due to the way in which veterinarians are recruited (see Box 2) and the administration is structured (departments are small), professional veterinary bureaucrats combine the two roles.

Public veterinarians have a complex relationship with other parts of the profession. ${ }^{7}$ They are by no means all members of the Swiss Veterinary Society (SVS), which has almost 3000 members ( $90 \%$ of the profession). The number of public veterinarians who are members of the SVS has decreased from 131 in 2010 to 108 in 2018, out of a total of around 170, representing a membership rate of 77 to $64 \%$. About half our interviewees are members of the SVS: 2 out of the 4 working at the federal level and 10 out of 18 at the cantonal level.

\footnotetext{
${ }^{7}$ It should be noted that the administrative services are not structured according to the division between rural and urban veterinarians, but according to four themes: 'primary production control', 'animal health' (including the monitoring of epizootics and zoonoses and of medicinal products), 'animal protection' (including animal welfare and the supervision of animal experiments) and 'veterinary laboratories'.
} 
In Switzerland, veterinarians train at the 'Vetsuisse' faculties in either Bern or Zurich. The studies, in German, last five years with a specialisation from the fourth year in either 'livestock', 'pets', 'horses', 'biopathology', 'biomedical research' or 'veterinary public health', the last option being a latecomer dating from the creation of a Veterinary Public Health Institute in 2009. For the non-clinical route, the final year is mainly carried out in the clinics or pathology institutes at the two universities. Swiss veterinarians do not need to follow 'classes préparatoires' before entering veterinary school as veterinarians in France do. For a long time, Swiss professional-bureaucrats trained 'on the job'. In 2011, two new legal texts, the 'Ordinance on the training, further training and continuing education of people in the public veterinary service' and the 'Ordinance on the training and examination of persons responsible for the enforcement of food law', were enacted to professionalise administrations responsible for food safety. Either before obtaining a position in the state services or once in post, veterinarians must obtain a 'Certificate of competence as official veterinarian' through practical and theoretical training (knowledge of legislation) followed by an examination before a peer committee. They have to work at least $30 \%$ of a full-time equivalent.

The careers of public and private veterinarians gradually diverge. Access through continuing education rather than competitive examination can make it easier for practitioners to transition into administration. Among our interviewees, public veterinarians presented the administrative route as more stable and predictable. For those with few inherited financial and social resources, it is an alternative to liberal practice, which is not very conducive to ambitious career development. It also offers an opportunity to those for whom the academic route has proved too challenging or who experience health problems at work. They give meaning to their work by contrasting the collective dimension of public health with the individual and routine approach of liberal practice and by pointing out that they have to respond to emergencies such as epizootics or problems in primary production likely to contaminate food. In our sample, 14 out of 26 public veterinarians briefly worked in private practice (between one and three years on average) after finishing their studies, the only time that they experienced clinical use of antibiotics. Those who moved to an administrative career later - between five and fifteen years after graduation - were active in research, mainly public funded research, but did not focus on antibiotics. Having obtained their diplomas in veterinary medicine more than twenty years ago $(n=16)$ or more than ten years ago $(n=9),{ }^{8}$ the veterinarians interviewed, even from different generations, considered that the subject of antibiotic resistance was only touched upon during their training.

Box 2 Veterinary bureaucrats and practitioners: career differentiation

These figures suggest that veterinary bureaucrats are at a certain remove from the SVS. One reason for this is that membership of the national organisation is not compulsory in order to practice; another is that the heads of the cantonal veterinary departments have their own association, the Association of cantonal veterinarians. In sum, administrative veterinarians are vastly outnumbered by the 1724 practising veterinarians in the SVS (the rest of the members work in research or for private companies), of which $60 \%$ are women who tend to specialise in small animals rather than livestock (Surdez 2009). In contrast, only $41 \%$ of administrative veterinarians are women, which puts paid to the idea that this is a particularly female segment of the bureaucracy. These few figures show that the regulation of this profession is not entirely controlled by the state, unlike in France, where the state plays a central role and membership of the Order is compulsory (Bonnaud and Fortané 2018).

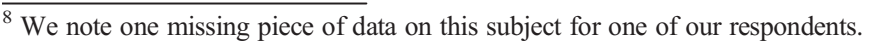




\section{The commitment to reform and control before AMR policies}

Although the problem of antibiotic resistance may now be formulated differently, with an emphasis on the One Health principle, the public policy put in place to deal with it is part of a much long process.

Since the 1990s, and throughout Europe, administrative entities involved in animal health and food safety have been restructured with the aim of reforming modes of regulation and of limiting health risks and crises (Janning 2008; Ollivier 2013; Thomann 2018). These changes have moved veterinary affairs away from agriculture ministries and closer to health ministries. The number of public veterinarians is said to have increased, as well as their room for manoeuvre and their legitimacy, both within central and decentralised administration (Alam 2007; Alam 2009, for England and France). Different administrative structures are expected to collaborate more closely (Jerolmack 2013), and certification procedures (especially for services and laboratories) have been entrusted to private actors (Verbruggen and Havinga 2017). Public policies to combat antibiotic resistance, which have been gaining prominence at the global level since the 2000s and especially 2010, continue to promote coordinated action between human and veterinary medicine.

In Switzerland, in contrast with the public debates here and elsewhere in response to the health crises of the 1990s, reforms to antibiotic use in veterinary medicine were almost exclusively discreetly negotiated between the state and veterinarians, without public intervention by politicians or media coverage. ${ }^{9}$ The topics discussed were the policy for regulating therapeutic products and the veterinary profession's monopoly on the distribution of medicinal products.

The first major reform was revising the 'Federal ordinance on veterinary medicinal products', finalised in 2004 (Sager et al. 2014; Thomann et al. 2018), which concerns medicinal products and specialisations as a whole. It increased the capacity of federal and cantonal veterinary services to monitor veterinarians' work by introducing the obligation to document prescriptions in a logbook and for practices' medicine cabinets to be inspected. This new mandate gave veterinary bureaucrats greater authority over practising veterinarians. The SVS, which has been taking a close interest since the 2000s, asked its members to accept the new arrangements, in order to avoid the more drastic reform of a ban on sales, which it firmly opposes. ${ }^{10}$

Implementing checks proved particularly difficult, especially when it came to medicinal products prescribed by veterinarians on an earlier visit and stored by farmers. This left its mark on our interviewees:

It was very badly received [...] I experienced this period: 'What's this? It's impossible, it's an insurmountable constraint' from both veterinarians and animal keepers. (Vet3, head of department, 46 years old, canton 1, 11/12/2015)

\footnotetext{
${ }^{9}$ In this period, regulations of veterinary medicinal products varied from country to country. For example, in Denmark, which sets a benchmark, practitioners were banned from selling antibiotics and were instead compensated for monitoring farms.

${ }^{10}$ Annual activity reports of the SVS, 2011-2017, available on the SVS's homepage.
} 
It's clear most veterinary practitioners are not happy when we arrive. But most of them think 'Well, if we have to do it, then let's do it'. And there are a few who are against it and get angry. We have to live with it... (Vet17, employee, 56, canton $3,03 / 02 / 2017$ )

The heads of the cantonal services do not have sufficient human resources to inspect private practices, which is all the more delicate as inspections involve peers and a network of acquaintances (Thomann et al. 2018). Indeed, the veterinary departments of two of the cantons that we investigated entrusted the inspection of medicine cabinets to neighbouring cantons.

The next stage came in 2010, with the revision of the 'Veterinary Therapeutic Products Act'. The SVS made its voice heard and acted as an intermediary, advocating to drastically reduce so-called 'reserve' antibiotic use in animal health ('reserve' antibiotics being those that should only be prescribed as a last resort for humans). The Society consequently encouraged practitioners to carry out laboratory diagnostics in order to assess precisely whether antibiotics are necessary and to promote both regular check-ups of herds and vaccination programmes. But it also fought to retain veterinarians' right to sell medicinal products, using a range of arguments: financial (their sale is an important source of revenue), expertise (veterinarians ensure that prescriptions are respected), client convenience (emergency access and treatment are facilitated) and the fact that in certain German-speaking cantons doctors are allowed to sell medication.

The administrative management of the antibiotic resistance problem over this period can thus be described as the convergence of two processes: firstly, the gradual implementation of a system of checks on antibiotics involving veterinary departments and practitioners' representatives and, secondly, the One Health framing of the problem, which aims to respond to the call of international organisations (World Health Organization, World Organization for Animal Health, European Union) and entails further state regulation. The ability of state veterinarians to influence the outcome would henceforth depend on their relationships with other professional bureaucrats, at both the federal and cantonal levels.

\section{The division of labour among bureaucrats: delegation or increased legitimacy of veterinarians?}

From May 2015, states were strongly encouraged to develop national action plans to address antibiotic resistance. In Switzerland, the Strategy on Antibiotic Resistance (StAR), which officially involves the Offices of human health, veterinary health, agriculture and the environment to the same degree, was adopted in November 2015 (Box 1). As we shall see, veterinary bureaucrats managed to maintain control over the development of measures concerning veterinary medicine and thus over their professional territory in relation to other administrative entities. For the professional bureaucrats of the other Offices, recognising veterinarians' ownership of this problem in their area was also a way of delegating the work to them and of making them responsible for the success of the action plan. As for the cantonal veterinarians associated with implementing it, as bureaucrats in direct contact with practitioner veterinarians 
(building on Lipsky's work on street-level bureaucrats, see Hupe and Hill 2007), those close relationships raised dilemmas for them.

\section{Federal veterinary bureaucrats making AMR a priority}

In Switzerland, it was managers and staff in the federal Offices who made AMR a priority. Assuming responsibility for it was a kind of test of their practical and symbolic legitimacy. Would they be able to set up homogenous monitoring systems throughout the country, particularly after having been restructured (see section 1 above)? They took on the role of bureaucrats who could see the big picture and, as such, took responsibility for anticipating crises and convincing cantonal bureaucrats to participate in implementing the plan. Among the administrative entities involved, the Communicable Diseases Division within the Federal Office of Public Health (FOPH) coordinated the various measures planned:

OK, so this is a very important activity for which we have also received quite substantial new resources. We are the ones who started this project or who initiated the joint strategy project with the other departments. (M1, doctor, FOPH, 58 years old, Bern, 02/11/2015)

The doctors, epidemiologists and social scientists in this division saw the StAR as an opportunity to strengthen their position in relation to the other Offices by promoting a crosscutting approach which employed the prevention and communication strategies used for infectious diseases:

The WHO's first action plan was a long time ago, but it didn't play such an important role, and I think it's because we were thinking in too much of a sectorspecific way [...] and I think that the mindset is different now. (B1, project manager biologist, FOPH, Bern, 02/05/2016)

However, the professionals of this Office took great care to empower the different types of professionals and to preserve their field of activity ('Everyone must get their own house in order', M1). On the one hand, their limited competence in veterinary medicine prevented them from interfering in the specific jurisdiction of veterinarians. Thus, one senior doctor (M1) said that he discovered during initial meetings that, in veterinary medicine, data on resistance concern dead animals more than those under treatment, due to the cost of antimicrobial susceptibility testing, whereas the opposite is true in human medicine; it was therefore necessary to design sector-specific monitoring systems. On the other hand, the aim was to rally the veterinarians of the Federal Food Safety and Veterinary Office (FSVO) who, in 2015, had just been transferred to the Department of the Home Affairs, to a common strategy focused on prevention.

For the FSVO, the challenge with the StAR was to institute systems for monitoring veterinary medicinal products, primarily antibiotics, on a national scale by enlisting cantonal veterinarians. The aim was to demonstrate that the veterinary profession was capable of self-regulating its use of antibiotics, so that, practically, a broad variety of 
antibiotics remained available and, symbolically, veterinarians avoided stigmatisation. For one veterinarian in a senior position at the FSVO, antibiotic resistance was an opportunity to move the profession towards a more prevention-oriented veterinary medicine. With a view to 'converting' practitioner veterinarians, shared by most FSVO staff members, he wanted to see expert veterinary advice symbolically and financially re-evaluated, relative to the prescription and sale of medicinal products, mainly antibiotics:

It means this: if you are a farmer and I can advise you on how you can fatten your calves without using antibiotics, and if it takes me hours to explain this to you, I should be able to earn my money with this advice, and not by selling you medicinal products. (Vet7, FSVO, 57, Bern, 02/02/2016)

However, the FSVO does not really have the leverage to bring in this new pricing system, since the profession sets the price for services and the StAR does not allocate any financial resources for this. This senior veterinarian set himself a more attainable objective, which fell within his remit: strengthening the system for monitoring the tonnage of antibiotics used in veterinary medicine:

The aim is to have an overview of who, when and what quantity of antibiotics are used. That is our goal, that is my goal. (Vet7)

Thus, a group of veterinary bureaucrats involved in monitoring the veterinary profession at the federal level asserted itself within the FSVO, with those responsible for the 'human health' side letting them decide on the best course of action. But were these veterinarians challenged by professionals working in or with food safety units?

\section{Other professional bureaucrats' contribution to defining AMR as an animal health problem}

The measures that veterinary bureaucrats advocate under the StAR also depended on the dynamics of the groups of bureaucrats involved in food safety and animal health issues, mainly chemical engineers and agronomists.

In Switzerland, chemists, whether chemical engineers or laboratory technicians, are the main professionals involved in monitoring processed products, through both scientific analysis and administrative procedures. Since they had been grouped with veterinarians in food safety units at the federal level and in most cantons in the course of the decade from 2010, they could have influenced the policies to combat antibiotic resistance. Chemical engineers had a very different approach to that of veterinary bureaucrats. This can be explained by their training (prestige of the discipline in Switzerland, periods in the private sector, see Surdez et al. 2018) and their monopoly on a certain type of analysis, among which the antimicrobial susceptibility testing (this laboratory technique targets infectious agents in order to determine their resistance to antibiotics). From their point of view, their main task was to monitor foodstuffs, including for fraud, an area which they did not associate at all with monitoring 
agricultural production. Consequently, although they did not deny the issues around AMR, according to our analysis of interviews, they associated it with two main items: 'we are in the background' and 'veterinarians'. In their order of priorities, it was on a par with pesticides, polychlorinated biphenyls (PCBs), genetically modified organisms (GMOs) or nanoparticles. The chemists framed AMR as a specifically human and animal health issue and not as a food safety issue. From this point of view, managing the problem involves veterinarians controlling antibiotic use further back in the food chain, as this cantonal chemist expressed it:

In the end, it is the use [of antibiotics] that is central, in production, I mean. We must intervene as far back in the chain as possible [...] Yes, yes, legally it is not relevant whether bacteria are resistant or not. It is a public health problem because antibiotics are no longer effective. It is not primarily a food safety problem, but a medical problem. Here I am speaking from the point of view of our legal mission of implementation. (Chem6, cantonal chemist, 50 years old, Bern, 30/09/2016)

By framing the issue in this way, they minimised their own responsibility and emphasised the veterinarians' responsibility. They did not envisage changing how they analysed samples and carried out susceptibility testing, nor the standards that they followed. In practical terms, neither the procedures for measuring antibiotic residues in food nor the tolerated amounts changed. The use of antimicrobial susceptibility testing seemed to them to be a method that would be difficult to roll out more widely for reasons of cost (farmers would have to pay the veterinarian) and feasibility (the time it would take to obtain and analyse the samples would be at odds with the urgency of care). Although chemists acknowledged the presence of resistant bacteria in or on food, particularly with imported vegetables, they deemed monitoring all imports to be out of their remit and prioritised detecting bacteria (and not resistance) in locally produced food. They did not intend to change their area of operations, their professional mandate or their practices. Although they recognised the problem as a legitimate one, they tended to assign responsibility for it to their veterinary colleagues.

The bureaucrats from the Federal Office for Agriculture (FOAG) and the Federal Office for the Environment (FOE), who are officially stakeholders in the StAR, did not consider AMR to be a priority problem either. ${ }^{11}$ This was perhaps particularly counterproductive, as the FOAG had a potentially powerful tool with which to influence the behaviour of livestock farmers. Indeed, in Swiss agricultural policy, farmers receive subsidies, known as 'direct payments', on condition that they comply with criteria defined and monitored by the FOAG. Although there have been recent discussions within the FOAG on using part of these subsidies to reward prevention and reduced antibiotic use, this lever has not yet been put to use.

\footnotetext{
11 In a joint report by the two offices (FOE and FOAG 2016) which sets out areas of action for the future of agriculture, antibiotic resistance is only a sub-heading, associated firstly with water treatment (traces of medicinal products not eliminated by treatment plants) and secondly with the spread of veterinary medicinal products in soils. The impact of plant protection products and traces of heavy metals in soils are given more space.
} 
While the FOAG has not yet taken any major steps towards preventing AMR, the agricultural engineers who worked there respected the scientific expertise of the FSVO veterinarians (in contrast to the chemists) and let them take the lead:

It is mainly the FSVO, because for everything that concerns animal health, for us, the FSVO is certainly the reference. So what we do is practical things. (Eng8, agricultural engineer at the FOAG, Bern, 12/07/2018)

This 'practical' aspect mainly concerned the safety of animal feed, following the longstanding ban on antibiotics as growth promoters, and restrictions on the use of additives in livestock feed. The role of the interviewee just mentioned was in fact to monitor these dossiers, to draw up up-to-date lists of the feedstuffs concerned and to inform veterinarians and farmers. It was only more recently that AMR was given greater prominence within the 'Safety of Primary Production' Unit of the FOAG, which used concerns for animal health as a means to legitimise financial support for indigenous agriculture:

We deem that better animal health leads to lower antibiotic use. That's kind of the strategy we have. And given the public discussion today, and the fear that it triggers, we would like to do something, in agriculture, to improve that. (Eng8)

For this reason, the FOAG developed policies to support research into farming systems that consume fewer antibiotics. Nevertheless, it acknowledged the leadership of the FSVO and veterinarians on this subject and did not seek to challenge it.

Thus, at the federal level, the various groups of professional bureaucrats seemed to be willing to define the problem of antibiotic resistance as an animal health issue for veterinarians to deal with. However, while federal public veterinarians seemed to take a leading role in defining AMR policy, cantonal veterinarians adopted different attitudes.

\section{Cantonal veterinarians faced with the dilemmas of proximity}

Indeed, due to the federal structure of the Swiss bureaucracy, implementing these policies requires the involvement of cantonal veterinary bureaucrats. The directors of the cantonal veterinary administrations (known as 'cantonal veterinarians') must respect the federal administration's guidelines and requests, while adapting them to the political, administrative and professional circumstances at cantonal level. In this interface position, they are directly responsible, together with their teams, for putting into practice procedures for monitoring and collecting data on antibiotic use in practices and, by extension, on farms. Faced with these challenges, they have developed two ways of reconciling the professional and bureaucratic dimensions of their role. Their greater or lesser endorsement of the new ways of managing food safety departments (certification and audit procedures resulting from new public management, see Surdez et al. 2018) is mirrored in whether they manage relations with practitioners in a more formal or more flexible way (Box 3). 
In describing their role, public veterinarians emphasise either their proximity with or distance from veterinary practitioners.

One cantonal head of department represents the first attitude (Vet4, cantonal veterinarian, 60 years old, canton 3,17/12/2015). She comes from an agricultural background and lives with a practising veterinarian. After obtaining her veterinary diploma in 1984, she spent over ten years in research on parasitology. Unable to find a stable position, she became a practitioner in a 'mixed' private practice (combining pet a livestock specializations), while also working at $50 \%$ in a cantonal administration. For her, practice alone was not 'dynamic' or intellectually challenging enough and she eventually focused on an administrative career in the same canton. Her experience as an independent practitioner is an essential reference point since she sees her role as dealing with practical issues, simply on a larger, public-health scale. She maintains regular contact with practising veterinarians who keep her informed of problems and reactions in the field (she used the German word for 'antennae'). She gave these close relationships as the reason for why she did not apply to run the whole department, which has included veterinary affairs and food safety since 2004. These relationships also allowed her to criticise peers who advocate certain measures without considering their practical feasibility ('it just bothers me when bureaucracy increases'). From this perspective, she downplayed the urgency and seriousness of antibiotic resistance and described the StAR as 'a big, floating, threatening cloud' to be dealt with. While she saw the need to 'sound the alarm', she believed that technical solutions would be found and that practitioners should not be 'asked too much'.

At the opposite end of the spectrum is the head of department in another canton (Vet3, head of department, 49 years old, canton 1,11/12/2015). His parents worked in the watchmaking industry and his grandparents were farmers. After a doctorate on gene therapy and a few months as a salaried veterinary practitioner (he never wished to open his own practice), he worked for ten years in the Porcine Health Sector within a semi-private, semi-public structure called SUISAG that aims to optimise pig production and breeding. There he acquired both management experience and experience of advising farmers. Aiming to further his career, he developed his skills in veterinary public health and in the economic and safety aspects of food safety. He then branched off into the administration in his home canton, where he gradually climbed the ladder. He had a strict, 'rules are rules' discourse on applying standards and checks for antibiotic resistance, aiming for the same 'efficiency' that he sought for his department. He did not deny the need for veterinary medicine to be involved in the fight against antibiotic resistance, but underlined that this responsibility should be shared by human medicine and environmental departments.

Box 3 Professional bureaucrats between flexibility and formality

Cantonal veterinarians in two out of the four cantons in which interviews were conducted opted for a formal and strict conception of their role. They tended to follow national guidelines to the letter and to legitimise any action undertaken as part of the StAR. They had frequently taken additional training in team or project management, to help establish their career within the administration. From this perspective, an element of their role as a professional bureaucrat was introducing modernising reforms by promoting new professional practices. As for the cantonal veterinarians whose attitude towards management was less rigid and more oriented towards the veterinary profession, they emphasised their close relationship with their practitioner peers and with farmers and presented this proximity as the most effective and sustainable way of convincing professionals in the field to change their practices, including those concerning antibiotics. They downplayed the urgency of the problem of antibiotic resistance ('It is an important issue in the veterinary field, but one that is overestimated', Vet4) because they thought it is necessary to give veterinarians and farmers time to adapt to the new 
standards for supervising medicine cabinets. This close relationship led them, for example, to criticise the monitoring procedures for being at once too bureaucratic and ineffective at reducing antibiotic use. This retired cantonal veterinarian, who witnessed the implementation of procedures over many years, expressed the problem thus:

We can note that a veterinarian sells large quantities of antibiotics, except that if for his practice he sells large quantities of antibiotics and then he can justify, for example, if he sells medicinal concentrates, that he has the prescriptions that go with it, that all the papers are correctly filled out, but what do you want us to say to him? (Rvet1, retired cantonal veterinarian, 65 years old, canton 1, 14/03/2016)

Attitudes towards the problem of antibiotic resistance and the introduction of stronger supervision also varied from sub-unit to sub-unit within cantonal administrations. Thus, some veterinarians working in laboratories were closer to the chemists (see "Other professional bureaucrats' contribution to defining AMR as an animal health problem") in considering that the problem did not directly concern them. They put the onus first onto practising veterinarians and then onto their colleagues in charge of animal health units, as this veterinarian in charge of a laboratory testifies:

The question should be put to the customer-facing veterinarians because at present, whether it is for small animal medicine or livestock, antibiotics are still used a lot, sometimes even without a diagnosis. [...] There are probably a lot of habits that need to be changed. It's not going to be easy, I have the impression, seen from the outside, because it doesn't concern us directly. (Vet9, laboratory manager, 59 years old, canton 1,05/04/2016)

However, other veterinarians working in the laboratories were more mindful of the value of antimicrobial susceptibility tests and focused on prescribing habits gradually becoming more targeted, as this interviewee indicated, in a mixture of exhortation, wish, observation and identification with veterinary practitioners:

But don't forget to take samples in order to be able to provide more targeted antibiotic therapy. We can always change the protocols, so we take samples, we give what we hope will help the animal at least to overcome the acute phase, and then we start a more specific treatment. So yes, that's something that is, at least for trained veterinarians, I would say, for the last fifteen years, it's part of the routine. We have become used to not giving antibiotics just anyhow. (Vet11, laboratory veterinarian, 37 years old, canton 1, 20/06/2016)

The cantonal veterinarians seemed to be caught between the conflicting demands of their proximity to veterinarians and heightened monitoring procedures. Antibiotic resistance policies have thus led to a divergence or even a fragmentation of the group of veterinary bureaucrats most in contact with veterinary practitioners on a daily basis. 


\section{Professional bureaucrats and professional organisations drawing closer together at national level}

How have the steps in the implementation of the StAR influenced the objectives of the AMR policy and plan, with the veterinary profession being held accountable for the reforms undertaken? How have cantonal state veterinarians carried out their delegated mandate to monitor or even reduce the use of antibiotics in veterinary medicine? Has the implementation of concrete measures amplified the difficulties and dilemmas raised in the previous phases (see Parts 1 and 2)? We will examine two main tools of public action, a therapeutic guide for practitioners and a database detailing the distribution of antibiotics, and highlight the issues that they have raised for professional autonomy. From the point of view of the sociology of professions, this stage has led to unprecedented regulation, with the authorities now contributing to defining 'good clinical practice' (once the preserve of the professionals) and able to scrutinise prescriptions. However, this regulation was carried out in close negotiation and collaboration with the professional group, in this case through its representative organisation, the SVS.

In this crucial phase, the number of meetings between the FSVO, the Association of cantonal veterinarians and the SVS went up to three or four per year. From 2016, the SVS worked hard to strengthen ties with the veterinary bureaucracy (SVS Annual Reports 2016 and $2017^{12}$ and vice versa, with a closer collaboration between public and private actors being advocated as a means of increasing the efficiency of public policies without substantially increasing the costs to the federal administration (StAR Report 2015). ${ }^{13}$ The relationships between veterinary bureaucrats and practitioner representatives varied according to the system being put in place, ranging from an 'educational' stance of medical expertise that respected practitioners' professional territory to remote supervision using IT tools. Which instrument veterinary bureaucrats chose affirmed their autonomy from the rest of the profession to a greater or lesser degree.

\section{An 'educational' approach to standardising treatment}

Since the development of the StAR, the FSVO veterinarians have emphasised 'education'. This initially took the form of information sessions on the action plan for cantonal veterinary bureaucrats, then for practising veterinarians. The sessions were not organised systematically in each canton, but where heads of department wanted to give the plan official authority, sometimes to show that the orders came from 'above'. Those in charge of antibiotic resistance at the FSVO then undertook to enlist veterinary practitioners through a more professional, practical and scientific approach. They established a working group to develop a booklet entitled 'Prudent use of antibiotics. A therapeutic guide for veterinarians' (FSVO, 2016, 108 pages) which details the type

\footnotetext{
${ }^{12}$ For example, 'Today, the SVS is more frequently invited to participate in working groups and is included in decisions', 2016 Report, p. 17.

${ }^{13}$ See 'The various actors and interest groups have been involved from the outset in the development of the strategy, and they will be called upon to play a leading role in its implementation', p. 18.
} 
of antibiotic recommended for different animal species (especially cattle and pigs) according to diseases and symptoms. ${ }^{14}$

This group, led by an FSVO veterinarian, was composed of seventeen 'experts', including nine representatives from the two veterinary faculties in Switzerland, six SVS representatives and two salaried veterinarians from the Bovine Health Department and the Porcine Health Department, two semi-private advisory bodies. Its composition was the result of informal personal contacts, with the FSVO official asking a veterinarian employed by the SVS to recruit practitioners:

Actually, X (from the FSVO) phoned me and said: 'Hey, we'd like to do this and that. It would be nice if you joined in'. And then we say yes or no (laughs). And yes, it was very important that we be involved, because otherwise we wouldn't have had a chance, if we hadn't got involved (repeats) it would never have been accepted by the practitioners or outside. (Vet24, veterinarian employed by the SVS, Bern, 22/09/2017)

Here we can see how transactions between different types of actors from different segments of the veterinary profession got underway. The FSVO's professional bureaucrats set up the meetings but left the content development to the SVS. On the SVS side, increased state intervention in antibiotics led to a veterinarian being employed to specialise in the issue, when previously the permanent staff had only constituted of a lawyer, an accountant and secretaries. This new employee asked the presidents of the SVS sections that seemed most affected to nominate the best 'specialists'.

This group functioned as an interface between state and non-state veterinarians, in which they could discuss professional issues, at the intersection between the political arena, the workplace arena and the public arena (in the sense of clients and public debate), which sociologists of professions identify as arenas where issues around professional regulation are debated (Hénaut 2016). State veterinarians used this forum to produce a tool, the 'therapeutic guide', and to give it both practical and scientific legitimacy. The form to be given to the recommendations was discussed in the group. It was possible to include the idea of 'good practice' in the guide by playing on the word 'recommendation' - in the sense of both advice and instruction - in order to respect both scientific standards ('state of the art', p. 3), legal standards and professional ethics ('the careful and conscientious exercise of the profession as required by the respect of professional duties according to the law on the medical professions', p. 3). The emphasis placed on scientific standards by both veterinary bureaucrats and SVS representatives paradoxically avoided stigmatising practitioners: thus, the two members of the working group whom we interviewed considered it normal that practitioners would not have time to keep up to date with the latest publications given their difficult working conditions (Vet24; Vet25, researcher at the veterinary faculty, Bern, 25/09/ 2017).

\footnotetext{
${ }^{14}$ As part of a parallel research programme, a professor of pharmacology and toxicology has created an internet portal allowing veterinarians to consult the classes of antibiotics recommended for different treatments.
} 
Focused on the notion of 'prudent use', the guide defined the various classes of antibiotics, 'critical' and 'reserve', but also the dosages, frequency and duration of treatments and recommended an antimicrobial susceptibility test before changing products. On the other hand, this first version made no mention of preventive means or alternative treatments to reduce consumption in animal husbandry, which was queried in parliament, ${ }^{15}$ thus highlighting what those consulted had taken for granted.

Despite precautions taken by the FSVO, when the guide was presented at public meetings, the more reluctant practitioners questioned the degree of standardisation and the binding nature of these recommendations. They expressed fears to veterinary bureaucrats and the SVS (Vet24) that these guidelines would, on the one hand, give rise to legal action on the part of farmers if they were not followed and, on the other hand, that they would function as a sort of 'blueprint' or 'recipe' that would minimise their professional expertise by allowing farmers to decide on the use of antibiotics, a decision that had hitherto been the monopoly of the veterinary profession. In dealing with antibiotic resistance, state veterinarians were thus faced with issues around the definition of roles and the limits of a professional monopoly, as well as around recommending alternatives to antibiotics.

\section{Requiring practitioners to provide individualised data}

In addition to this educational tool, the veterinary bureaucrats at the FSVO aimed to implement a monitoring system, ${ }^{16}$ a cornerstone of all national action plans against antibiotic resistance. This more coercive instrument would reinforce the supervision of medicinal products, especially antibiotics, prescribed by practitioners, without abolishing inspection visits, the difficult beginnings of which we have noted. The objective is to systematically collect the data on the treatments administered by each veterinarian, whether rural or urban, for each of their clients. Establishing these official statistics raises crucial questions, both practical (Who is responsible for this work? How precise should it be?) and in terms of who should have access to them (the administration, the profession, researchers, the agri-food industry, the public?).

In line with previous regulations (2004 and 2010, see Part 1), the FSVO is committed to developing a more accurate tool than the aggregated quantities by sector supplied by firms, based on the logbooks that veterinarians and farmers have to keep. Despite the StAR's One Health framework, this level of monitoring of individual private practitioners is not currently matched in human medicine, where the data focus on hospitals. This can be seen as indicative of the weakness of the veterinary profession, which is nonetheless trying not to lose control of the situation completely.

The model that has been endorsed since 2016 in negotiations between the federal and cantonal veterinary bureaucrats and the SVS is to ask individual practitioners to report data to the FSVO. Veterinarians at the cantonal level simply spot-check the data entered into the computer system. Unable to stop this, the professional organisation has emphasised its willingness to cooperate and to be transparent while at the same time

\footnotetext{
15 The parliamentary motion is available on the homepage of the Swiss parliament: https://www.parlament.ch/ de/ratsbetrieb/suche-curia-vista/geschaeft?AffairId=20183089.

${ }^{16}$ Depending on the country, monitoring may include establishing an epidemiological surveillance system for resistant bacteria, which involves monitoring cases of resistance, and a database on antibiotic use.
} 
fiercely discussing technical arrangements and financial compensation. The veterinarian employed by the SVS relayed this position:

So the veterinarians have no problem with transmitting data so that the Confederation knows which medicinal products they are prescribing, but they have a lot of trouble with the fact that they have to do it themselves on their computer, because it takes time. (Vet24, veterinarian, SVS, Bern, 22/09/2017)

The occupational group agreed to provide the data. ${ }^{17}$ In return, the designers configured the software for collecting the data to be compatible with standard practice management software (to avoid having to enter information about the same client twice) and to automatically calculate waiting times (before the animals can be slaughtered or milk sold), based on the time and method of injection of the antibiotic. Practitioners cooperate with this system, which is still in the experimental phase, on the condition that individual data are confidential and because they find it useful in practice. It is also to demonstrate that they are not afraid of the scrutiny of their fellow bureaucrats and that their prescriptions are not motivated by profit, as the representative of the SVS has argued:

It's perfidious to think that someone intentionally sold it for... because there are other things one can sell. (Vet24)

This professional defence strategy does not rule out collective and individual opposition, which manifests through negotiations over compulsory data for each kind of animal. However, it also preserves the profession's business model, which remains based on the sale of medicinal products. Beyond encouraging words, it is difficult for public veterinary departments to promote remuneration for advice and prevention, as the profession remains very much oriented towards liberal practice and geographically scattered. ${ }^{18}$ Although the introduction of automated data transmission involved representatives of practising veterinarians to make it acceptable, it could also have a ratchet effect and the SVS may not be consulted as much on this subject in the future.

\section{Conclusion: concerted changes to the profession and its regulation}

Policies developed to address the problem of AMR in veterinary medicine are structured by the ambivalent relationships of veterinarians working for the administration with their professional group of origin. Trained as veterinarians but having branched off into public administration in the course of their career, these professional bureaucrats adopt different positions towards monitoring antibiotic use, ranging from instituting

\footnotetext{
${ }^{17}$ According to a dual tracing system, firms would also be obliged to indicate to whom they have sold what quantities, which would be quite an achievement: 'They are being put on the spot...' (veterinarian specialised in IT systems, FSVO, 35, Bern, 17/07/2018).

${ }^{18}$ In 2017, 617 veterinarians worked in individual practices, 388 in group practices and 281 were salaried (SVS Report 2017).
} 
binding public health measures to understanding the issues related to professional practice. Depending on their place in the administrative hierarchy, they tend to take on either a role of reformer-innovator involving mediation and pedagogy, or one of supervisor or spokesperson for practitioners. Although, based on the One Health principle, other administrative professionals (mainly doctors, chemical engineers or agronomists) can intervene in the implementation of the national action plan, it is ultimately the federal veterinary bureaucrats who define and implement the measures, in particular a much-discussed database on individual antibiotic use. However, they cannot or do not wish to redefine prescribing practices without negotiating with the organisation that represents the profession, the SVS, and agreeing to at least some of its demands, even if some instruments may have ratchet effects.

The autonomy of the veterinary bureaucrats from the rest of the profession is therefore limited, in particular due to the monopolistic position of the SVS compared with the association representing administrative veterinarians. Moreover, these actors share some common interests, if not around the gradual transition towards a more reasonable use of antibiotics, then at a more structural level around the preservation of the profession's income.

At this stage of the study, no unprecedented coalitions between segments of the professional group and segments of the administration have emerged to implement a paradigm shift, such as payment for prevention becoming widespread. In the interests of the entire profession being treated consistently, all veterinary practitioners, including urban ones, will certainly be required to provide information on the antibiotics that they prescribe, even though urban practitioners are far less likely to be compensated for preventive services than rural ones. As the database for the systematic collection of data on the use of medicinal products is still under construction, we are not in a position to predict the exact uses to which state veterinarians will put those data, nor whether the systematic collection of data will lead to a real reduction in the quantities and types of antibiotics used. It will be interesting to see how the law banning the prophylactic use of antibiotics, adopted by the European Parliament in 2018, will be applied-some interviewees stating that the veterinary profession will always have the right to use antibiotics preventively if they deem it necessary, but that breeders will not be allowed to keep and administer them themselves.

A detailed examination of the public policy instruments put in place within a country reveals that methods of regulating antibiotic resistance and the profession change gradually, on the basis of previous arrangements. In Switzerland, given the relatively recent increase in public veterinarians' operational capacity and legitimacy, state intervention still relies heavily on the professional organisation, which has long used its clout to get the public authorities to endorse how professionals, both practitioners and bureaucrats, define how the profession should function, which amounts to selfregulation (Demazière 2018). On the basis of the results presented here, it will be particularly interesting to carry out a comparative analysis with other national plans against AMR in Europe which, despite their family resemblance, differ in the details of the measures taken and in the configurations of stakeholders, particularly in terms of the power relationships between the medical and veterinary professions, between sectors of the administration or between the veterinary profession and agricultural interest groups. 
Funding Open access funding provided by University of Fribourg.

Open Access This article is licensed under a Creative Commons Attribution 4.0 International License, which permits use, sharing, adaptation, distribution and reproduction in any medium or format, as long as you give appropriate credit to the original author(s) and the source, provide a link to the Creative Commons licence, and indicate if changes were made. The images or other third party material in this article are included in the article's Creative Commons licence, unless indicated otherwise in a credit line to the material. If material is not included in the article's Creative Commons licence and your intended use is not permitted by statutory regulation or exceeds the permitted use, you will need to obtain permission directly from the copyright holder. To view a copy of this licence, visit http://creativecommons.org/licenses/by/4.0/.

\section{References}

Abbott, A. (1988). The system of professions. Chicago: University of Chicago Press.

Alam, T. (2007). Quand la vache folle retrouve son champ. Une comparaison transnationale de la remise en ordre d'un secteur d'action publique. Doctoral dissertation, Université de Lille 2-Droit et Santé.

Alam, T. (2009). La vache folle et les vétérinaires. Récit d'une victoire inattendue et paradoxale sur le terrain de la sécurité sanitaire des aliments. Revue d'études en agriculture et environnement, 90(4), 373-398.

Bezes, P., Demazière, D., Le Bianic, T., Paradeise, C., Normand, R., Benamouzig, D., Pierru, F., \& Evetts, J. (2011). New public management et professions dans l'État : au-delà des oppositions, quelles recompositions ? Sociologie du travail, 53, 293-348.

Bonnaud, L., \& Fortané, N. (2018). L’État sanitaire de la profession vétérinaire. Action publique et régulation de l'activité professionnelle. Sociologie, 9(3), 253-268.

Chien, Y.-J. (2013). How did international agencies perceive the avian influenza problem? The adoption and manufacture of the 'one world, one health' framework. Sociology of Health \& Illness, 35(2), 213-226.

Demazière, D. (2018) La professionnalisation dans tous ses états. In F. Bajart, B. Crunel, C. Frau, F. Nicolas \& F. Parent (Dir.), Professionnalisation(s) et Etat. Une sociologie politique des groupes professionnels (pp. 291-307). Villeneuve d'Ascq, Presses universitaires du Septentrion.

European Commission. (2017). A European one health action plan against antimicrobial resistance (AMR). Brussels, European Commission.

Federal Food Safety and Veterinary Office (FSVO). 2018. ARCH-Vet. Rapport sur les ventes d'antibiotiques et l'antibiorésistance en médecine vétérinaire en Suisse (In French and German only). https://www.blv. admin.ch/blv/fr/home/tiere/tierarzneimittel/antibiotika/vertrieb.html

Federal Office for the Environment (FOE) \& Federal Office for Agriculture (FOAG). (2016). Objectifs environnementaux pour l'agriculture. (In French and German only). https://www.bafu.admin.ch/bafu/fr/ home/themes/biodiversite/publications/publications-biodiversite/objectifs-environnementaux-agriculture. html.

Federal Office of Public Health (FOPH). (2015). Strategy on Antibiotic Resistance Switzerland (StAR). https:// www.blv.admin.ch/blv/en/home/das-blv/strategien/nationale-strategie-antibiotikaresistenzen.html.

Federal Office of Public Health (FOPH) \& Federal Food Safety and Veterinary Office (FSVO). (2015). Antibiotic resistance-Goal/strategy. Booklet. https:/www.bundespublikationen.admin.ch/cshop_bbl/ b $2 \mathrm{c} / \mathrm{start} /(\mathrm{c}$ area=0024817 F $68691 \mathrm{EE} 1 \mathrm{~B} 4 \mathrm{AF} 0 \mathrm{C} 6 \mathrm{E} 78170 \mathrm{EF} 0$ \& $\mathrm{cite} \mathrm{m}=$ 0024817F68691EE1B4AF0C6E78170EF0A0D3C100DD2F1EE59CE0ECA992658115)/.do.

Fortané, N. (2016). Le problème public de l'antibiorésistance en élevage : essai de généalogie et caractérisation. Questions de communication, 29, 49-66.

Freidson, E. (2001). Professionalism: The third logic. Cambridge: Polity Press.

Grant, W., \& Greaves, J. (2009). State veterinarians: the construction of rural expertise in England. Paper for the European Society for Rural Sociology Congress. Vaasa.

Hénaut, L. (2016). A l'origine de la dynamique des professions. Interdépendance ou interactions ? In D. Demazière \& M. Jouvenet (Dir.), Andrew Abbott et l'héritage de Chicago, vol. 2, (pp. 186-199). Paris, Éditions de l'EHESS.

Hinchliffe, S. (2015). More than one world, more than one health: Re-configuring interspecies health. Social Science \& Medicine, 129, 28-35.

Hobson-West, P., \& Timmons, S. (2016). Animals and anomalies: An analysis of the UK veterinary profession and the relative lack of state reform. The Sociological Review, 64(1), 47-63. 
Hupe, P. L., \& Hill, M. J. (2007). Street-level bureaucracy and public accountability. Public Administration, $85(2), 85-102$.

Janning, F. (2008). Risk regulation without political conflicts? Regime structures in food safety politics in Germany, Great Britain and the Netherlands. German Policy Studies, 4(1), 67-106.

Jensen, C. S., Beck Nielsen, S., \& Fynbo, L. (2018). Risking antimicrobial resistance. In A collection of onehealth studies of antibiotics and its social and health consequences. Palgrave MacMillan.

Jerolmack, C. (2013). Who's worried about turkeys? How 'organisational silos' impede zoonotic disease surveillance. Sociology of Health \& Illness, 35(2), 200-212.

Noordegraaf, M. (2007). From 'pure' to 'hybrid' professionalism. Present-day professionalism in ambiguous public domains. Administration and Society, 39(6), 761-785.

Noordegraaf, M. (2013). Reconfiguring professional work: Changing forms of professionalism in public services. Administration and Society, 48(7), 783-810.

Ollivier, B. (2013). Quand les vétérinaires et les animaux font l'Europe : l'action publique européenne en santé animale, une institutionnalisation fragmentée. Doctoral dissertation, Paris, Institut d'études politiques.

Sager, F., Thomann, E., Zollinger, C., Van der Heiden, N., \& Mavrot, C. (2014). Street-level bureaucrats and new modes of governance: How conflicting roles affect the implementation of the Swiss ordinance on veterinary medicinal products. Public Management Review, 16(4), 481-502.

Surdez, M., Debons, J., \& Piquerez, L. (2018). De la fourche à la fourchette : une recomposition des territoires d'activité chez les professionnels suisses du contrôle sanitaire des aliments ? SociologieS, Dossier Identités au travail, identités professionnelles.

Thomann, E. (2018). Customized implementation of European Union food safety policy: United in diversity? Palgrave Macmillan, International Series on Public Policy.

Thomann, E., Hupe, P., \& Sager, F. (2018). Serving many masters: Public accountability in private policy implementation. Governance, 31, 299-319. https://doi.org/10.1111/gove.12297.

Verbruggen, P., \& Havinga, T. (2017). Hybridization of food governance: An analytical framework. In P. Verbruggen \& T. Havinga (Eds.), Hybridization of food governance: Trends, types and results (pp. 1-28). Cheltenham: Edward Elgar.

Woods, A., Bresalier, M. C., Cassidy, A. M., \& Mason Dentinger, R. (2017). One health and its histories: Animals and the shaping of modern medicine. Palgrave Macmillan.

World Health Organization (WHO). (2014). Antimicrobial resistance: Global report on surveillance. https:// apps.who.int/iris/handle/10665/112642.

World Health Organization (WHO). (2015). Global action plan on antimicrobial resistance. https://www. who.int/antimicrobial-resistance/global-action-plan/en/

World Organization for Animal Health (OIE). (2016). The OIE strategy on antimicrobial resistance and the prudent use of antimicrobials. https:/www.oie.int/fileadmin/Home/eng/Media_Center/docs/pdf/ PortailAMR/EN_OIE-AMRstrategy.pdf

Publisher's note Springer Nature remains neutral with regard to jurisdictional claims in published maps and institutional affiliations. 